\title{
Desain dan Analisis Pengukuran Viskositas dengan Metode Bola Jatuh Berbasis Sensor Optocoupler dan Sistem Akuisisinya pada Komputer
}

\author{
Warsito $^{*}$, Sri Wahyu Suciyati, dan Dyan Isworo \\ Jurusan Fisika, Fakultas Matematika dan Ilmu Pengetahuan Alam, Universitas Lampung, Bandar Lampung 35145 \\ Diterima 04-11-2010Ｄisetujui 28-05-2011
}

\begin{abstract}
It has been designed and analyzed the low cost viscometer using falling ball method, the sample analyzed is glycerin fluid at $20^{\circ} \mathrm{C}$. Two optocoupler circuits have been used as time measurement system of falling ball between two references point, light source used was infrared laser diode. The computer acquisition system use serial communication and it has been perfectly made and characterized. The velocity measurement system has $0.75 \times 10^{-1} \mathrm{~s}$ resolution, but the resolution of integrated system both of hardware and acquisition software, is about $10^{-1} \mathrm{~s}$. The theoretical viscosity value has been calculated and simulated to abtain the absolute viscosity value. This simulation results have been analyzed and compared with the experiment results. The correction factor for velocity calculation has been discussed and gave the optimum value of velocity correction factor (0.4425), regarding to the dimension of tube and ball used in this research. Based on the experiment, the viscosity of glycerin obtained was $1418.0309 \pm 1.6157 \mathrm{mPa}$.s., this value was with similar with the literatures and has a $0.57 \%$ of accuracy error $\left(\varepsilon_{0}\right)$.
\end{abstract}

Keywords: viscosity, falling ball method, real time acquisition record

\begin{abstract}
ABSTRAK
Telah didesain dan dianalisis alat ukur viskositas sederhana menggunakan metode bola jatuh, dengan sampel yang diuji adalah cairan gliserin pada suhu $20^{\circ} \mathrm{C}$. Dua rangkaian optocoupler telah digunakan untuk mengukur waktu bola jatuh antara dua titik acuan, sumber cahaya yang digunakan adalah laser dioda infra merah. Sistem akuisisi komputer menggunakan komunikasi serial dan semua sistem telah dibuat dan dikarakterisasi dengan baik. Sistem pengukuran kecepatan mempunyai resolusi $0,75 \times 10^{-1} \mathrm{~s}$, tetapi resolusi secara integral dari alat hanya mampu sekitar $10^{-1} \mathrm{~s}$. Nilai viskositas secara teori telah dihitung dan disimulasi untuk mendapatkan nilai viskositas absolut. Hasil simulasi telah dianalisi dan dibandingkan dengan hasil uji percobaan. Faktor koreksi untuk perhitungan kecepatan telah dianalisis dan memberikan nilai optimal faktor koreksi kecepatan sebesar 0,4425, yang mana nilai ini sangat dipengaruhi oleh dimensi tabung dan bola jatuh yang digunakan. Viskositas gliserin yang diperoleh pada percobaan sebesar 1418,0309 $\pm 1,6157 \mathrm{mPa}$.s., nilai ini sesuai dengan nilai yang ada di literatur lainnya dan memberikan nilai kesalahan ketepatan $\left(\varepsilon_{0}\right)$ sebesar $0,57 \%$.
\end{abstract}

Kata kunci: viskositas, metode bola jatuh, perekaman akuisisi data secara langsung

\section{PENDAHULUAN}

Viskositas suatu fluida merupakan daya hambat yang disebabkan oleh gesekan antara molekul-molekul cairan, yang mampu menahan aliran fluida sehingga dapat dinyatakan sebagai indikator tingkat kekentalannya. Nilai kuantitatif dari viskositas dapat dihitung dengan membandingkan gaya tekan per satuan luas terhadap gradien kecepatan aliran dari fluida. Prinsip dasar ini yang dipergunakan untuk menghitung viskositas secara eksperimen menggunakan metode putar, yaitu dengan

*Telp: +628154056557

Email: warsito@unila.ac.id memasukkan penghambat ke dalam fluida dan kemudian diputar. Semakin lambat putaran penghambat tersebut maka semakin tinggi nilai viskositasnya (Gottlieb 1979; Thibodeau 2004; Warsito et al. 2009).

Metode yang tidak merusak untuk mengukur nilai viskositas cairan juga dikembangkan dengan metode gelombang ultrasonik, yaitu mengukur cepat rambat gelombang ultrasonik pada cairan. Semakin cepat rambat gelombang semakin tinggi viskositas cairannya (Truell et al. 1969; Hinrichs \& Thuen 1985; Walters \& Jones 1996; Warsito et al. 2010). 
Metode lain yang sudah dikenal sejak lama untuk mendapatkan nilai viskositas adalah metode bola jatuh (falling ball method) dengan prinsip Hukum Stokes (Gambar 1) (Leont'ev \& Vakhrushev 1976; Lommatzsch et al. 2001; Fujita et al. 2003; Fujita et al. 2005; Brizard et al. 2005).

Mengacu pada Gambar 1, maka berlaku persamaan berikut:

$$
\begin{gathered}
\sum F=0 \\
F_{\text {apung }}+F_{\eta}+(-m g)=0
\end{gathered}
$$

Dengan memasukkan gaya apung $F_{\text {apung }}=\frac{4}{3} \pi r^{3} \rho_{1} g$ dan memasukkan gaya tahan dari Hukum Stokes $F_{\eta}=6 \pi \eta r v$ serta massa bola $m=\frac{4}{3} \pi r^{3} \rho_{0}$ ke dalam persamaan 1 , maka didapatkan penyelesaian untuk persamaan viskositas $(\eta)$ sebagai berikut:

$$
\eta=\frac{2}{9} \frac{r^{2} g}{v}\left(\rho_{0}-\rho_{1}\right)
$$

dimana $r$ adalah jari-jari bola, $g$ adalah percepatan gravitasi, $\rho_{0}$ adalah massa jenis bola, dan $\rho_{1}$ adalah massa jenis fluida.

Francis (1933), memberikan fungsi Efek Wall yang hingga sekarang menjadi rujukan utama pengembangan metode bola jatuh. Efek Wall tersebut merupakan parameter faktor koreksi dalam menentukan nilai viskositas cairan menggunakan metode bola jatuh disebabkan oleh rasio diameter bola $(d)$ terhadap diameter tabung $(D)$ mempengaruhi kecepatan jatuh bola. Faktor koreksi tersebut diberikan oleh persamaan berikut:

$$
C_{f}=\left[\frac{1-0,475 d / D}{1-d / D}\right]^{4}
$$

Persamaan 3 hanya berlaku untuk nilai bilangan Reynolds, $R e<1$ dan rasio $d / D<0,97$. Faktor koreksi ini juga dimanfaatkan pada pengukuran viskositas pada fluida tersuspensi menggunakan koefisien drag (Leont'ev \& Vakhrushev 1976). Brizard et al. (2005), mengembangkan teori yang dikemukakan Francis (1933), yaitu dengan memasukkan faktor bilangan Reynolds pada besaran kecepatan bola jatuh sebagai fungsi rasio antara diameter bola dan tabung yang disebut edge effects.

Pada metode bola jatuh, yang menjadi bagian penting adalah mengukur waktu jatuh dari bola yang dijatuhkan pada fluida. Sehingga yang menjadi perbedaan pokok berbagai pengembangan untuk metode bola jatuh ini adalah cara mengukur kecepatan bola jatuh. Lommatzsch et al. (2001), menggunakan metode kamera video untuk merekam proses bola jatuh kemudian citra diolah dan didapatkan kecepatan jatuhnya, dengan metode ini didapatkan waktu jatuh yang mempunyai ketelitian hingga $10^{-3} \mathrm{~s}$, metode ini juga dilakukan oleh Brizard et al. (2005). Pengukuran dengan menggunakan perekaman citra dilakukan dengan dua tahap, yaitu: 1) perekaman, dan 2) pengolahan citra dengan melakukan perbandingan antara dua citra saat bola jatuh melewati titik referensi pertama dan titik referensi kedua.

Pengukuran kecepatan bola jatuh menggunakan interferometer Michelson juga dikembangkan untuk mendapatkan nilai absolut dari viskositas cairan yang diukur (Fujita et al. 2003; Fujita et al. 2005). Untuk mendapatkan nilai viskositas, Fujita et al. (2005) harus melakukan pengolahan gambar sehingga didapatkan waktu jatuh dari bola.

Pada penelitian ini, dikembangkan sistem pengukuran nilai viskositas dari gliserin yang berbasis pada sensor optocoupler sebagai metode pengukuran kecepatan bola jatuh yang memberikan secara langsung nilai viskositas tanpa harus melakukan pengolahan bertahap dengan sistem gambar seperti yang dilakukan oleh Fujita et al. (2005). Faktor koreksi pada berbagai situasi juga disimulasi untuk mendapatkan nilai absolut dari viskositas. Analisis sistem akuisisi data pada komputer secara serial juga dilakukan, sehingga penelitian ini bersifat akuisisi secara langsung dan mudah dibawa (portable).

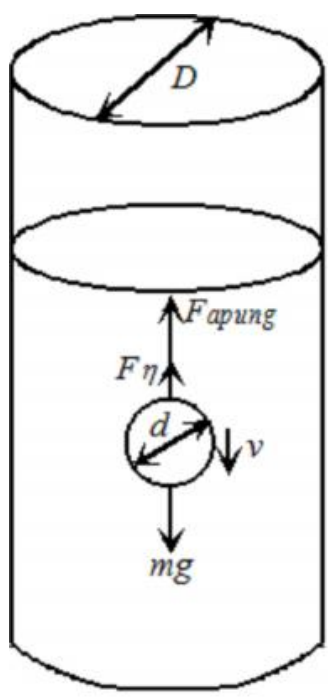

Gambar 1 Gaya-gaya yang bekerja pada bola (diameter $d$ ) yang jatuh dalam tabung fluida (diameter $D$ ) 


\section{BAHAN DAN METODE}

Sistem Mekanis. Sistem mekanis yang utama terdiri dari dua komponen yaitu: tabung kaca dengan diameter $4,7 \times 10^{-3} \mathrm{~m}$, panjang $1,7 \times 10^{-1} \mathrm{~m}$ dan bola besi yang mempunyai diameter $1,2 \times 10^{-2} \mathrm{~m}$ serta sebesar $7,643 \times 10^{3} \mathrm{~kg} / \mathrm{m}^{3}$ (Gambar 1).

Sistem Akuisisi Data. Blok diagram perancangan sistem seperti terlihat pada Gambar 2. Sistem terdiri dari dua sensor optocoupler yang masing-masing diteruskan ke rangkaian komparator, sinyal keluaran dari komparator diteruskan ke mikrokontroler AT89C51, dan selanjutnya terhubung ke komputer menggunakan komunikasi serial MAX 232 sebagai adaptor tingkat tegangan (Gambar 2). Dua sensor optocoupler yang dipergunakan adalah laser diode inframerah dan phototransistor, sensor 1 mendeteksi ketika bola melewati posisi sensor 1 dan sensor 2 memberikan respon berbeda ketika bola melewati posisi sensor 2 .

Kesesuaian tingkat arus dan tegangan Transistor Transistor Logic (TTL) dari sensor dilakukan oleh rangkaian komparator yang menggunakan komponen utama OpAmp 741, sehingga sinyal keluaran yang dihasilkan bersifat digital 'ada' dan 'tidak'. Sinyal keluaran ini diolah sehingga fungsi digital sudah sesuai dengan masukan yang diperlukan mikrokontroler. Pada mikrokontroler AT89C51 logika '1' jika tegangan sebesar 5 volt dan berlogika '0' jika tegangan bernilai 0 volt. Sedangkan pada komunikasi serial komputer, logika ' 1 ' tegangannya bernilai -3 sampai -25 volt dan logika '0' bernilai +3 sampai +25 volt. Adaptasi kedua perbedaan level tegangan serial ini, yaitu antara serial mikrokontroler dan serial komputer dilakukan oleh rangkaian RS-232 dengan menggunakan IC MAX 232.

Perancangan software terdiri dari: software pengendalian sinyal yang direkam ke dalam mikrokontroler menggunakan bahasa Asembler dan software akuisisi yang direkam ke dalam komputer sebagai pengatur sistem akuisisi data dari mikrokontroler serial dan pengolah sistem tampilan, software ini menggunakan bahasa Visual Basic 6.0.

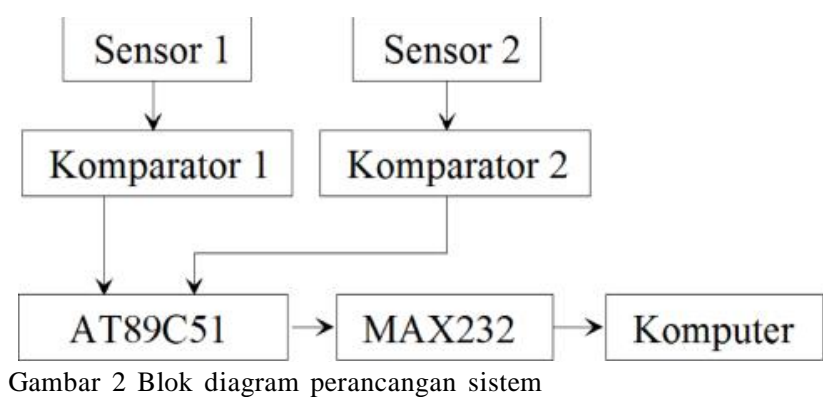

HASIL DAN PEMBAHASAN Analisis Sistem Pengukuran Waktu Bola Jatuh. Rangkaian sistem secara keseluruhan ditunjukkan pada Gambar 3, yang terdiri dari tiga bagian utama: rangkaian komparator, rangkaian pengendali mikro, rangkaian penguat tingkat tegangan TTL. Desain sistem secara keseluruhan merupakan pengembangan dari yang dilakukan oleh Brizard et al. (2005) dengan menggunakan dua sensor optocoupler phototransistor, sedangkan yang dilakukan oleh mereka adalah dengan menggunakan kamera vertikal CCD dan proses analisis dilakukan secara bertahap.

Rangkaian komparator pada Gambar 3 terdiri dari dua rangkaian komparator yang terhubung ke port P1.0 dan P1.1 dari mikrokontroler. Tegangan keluaran phototransistor diumpankan ke rangkaian komparator, jika tegangan keluaran lebih kecil dibandingkan dengan tegangan referensi pada komparator sebesar 2,46 volt, maka mikrokontroler menerima logika '0', hasil uji rangkaian komparator disajikan pada Tabel 1. Jika intensitas cahaya kecil, hambatan dari phototransistor besar sehingga menyebabkan tegangan keluaran kecil. Tegangan keluaran ini menjadi tegangan masukan $\left(\mathrm{V}_{\text {in }}\right)$ pada komparator. Kondisi komparator akan high jika $\mathrm{V}_{i n}<\mathrm{V}_{\text {ref }}$ sehingga mikrokontroler menerima logika ' 1 '. Demikian juga keadaan sebaliknya yaitu jika intensitas phototransistor kecil dan tegangan keluaran akan besar, selanjutnya karena logika komparator low jika $\mathrm{V}_{\text {in }}>\mathrm{V}_{\text {ref }}$ maka mikrokontroler menerima logika ' 0 '. Komunikasi antara keluaran komparator dengan mikrokontroler tidak memerlukan ADC karena sinyal keluaran sudah dalam tingkatan digital TTL dimana logika 1 untuk level tegangan sebesar 2,3-5 volt dan logika 0 untuk level tegangan 0-1,7 volt. Secara keseluruhan sistem rangkaian komparator telah berfungsi dengan baik, dimana tegangan keluaran pada rangkaian sensor dengan mode switch berbanding terbalik dengan intensitas cahaya yang diterimanya.

Mikrokontroler telah diprogram mengirim data serial '0' jika masukan dari P1.0 (terhubung ke rangkaian komparator 1) berlogika ' 1 ' dan mengirim data serial ' 255 ' jika masukan dari P1.1 (terhubung ke rangkaian komparator 2) berlogika ' 1 '. Data serial ' 0 ' bermakna logika digital 0 dan serial '255' bermakna logika 1 , sistem ini bekerja berdasarkan prinsip pensaklaran.

Secara keseluruhan foto sistem yang direalisasi seperti pada Gambar 4. Komunikasi serial yaitu data dikirim satu persatu secara berurutan selalu memerlukan suatu piranti UART (Universals Asynchronous Receiver Transmitter) 


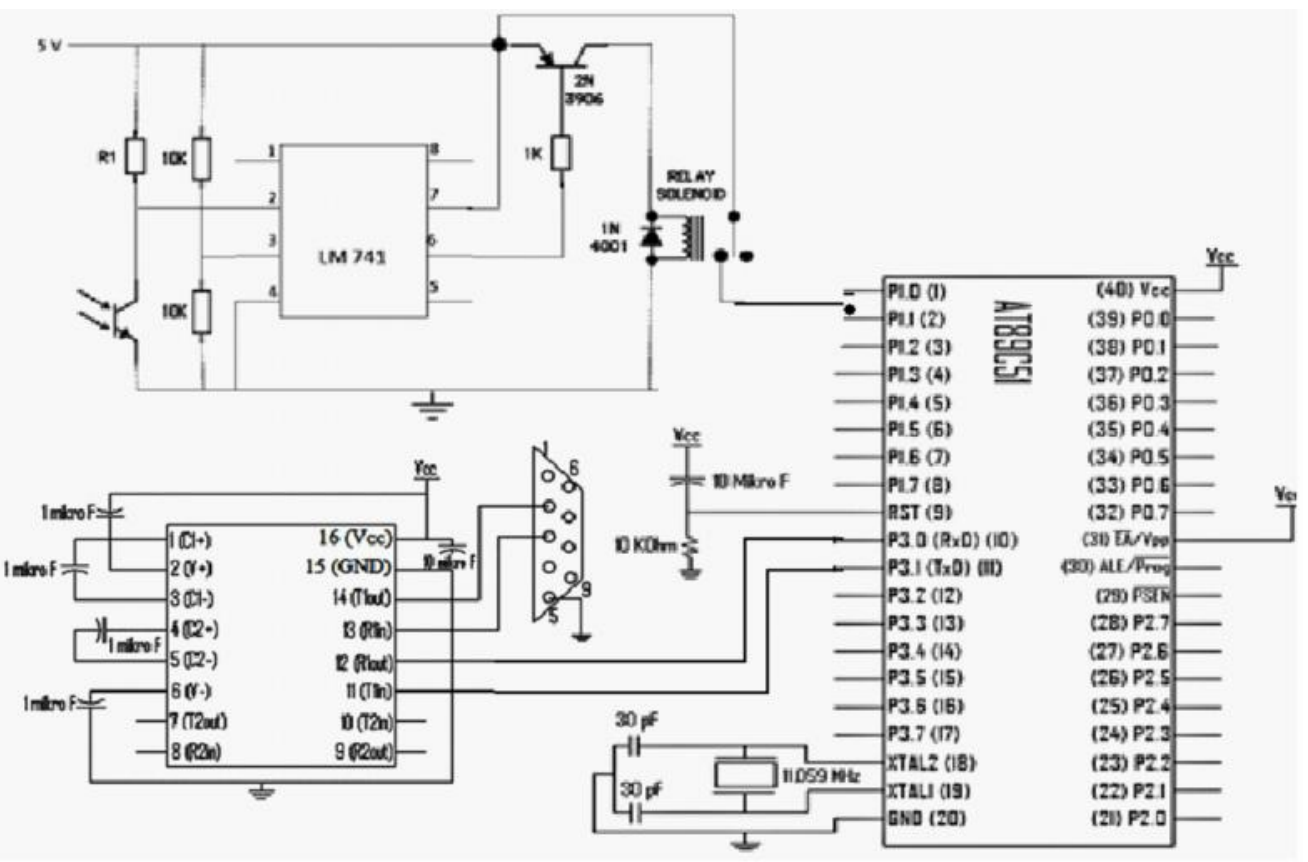

Gambar 3 Rangkaian secara keseluruhan dari sistem

Tabel 1. Hasil pengujian rangkaian komparator yang terangkai dengan phototransistor ketika ada dan tidak ada cahaya, tegangan referensi (V ref) sebesar 2,46 Volt

\begin{tabular}{cccc}
\hline \multicolumn{2}{c}{ Tidak ada cahaya } & \multicolumn{2}{c}{ Ada cahaya } \\
\hline Vin (Volt) & Vout (Volt) & Vin (Volt) & Vout (Volt) \\
\hline 4,55 & 1,92 & 0,39 & 4,49 \\
4,55 & 1,92 & 0,52 & 4,49 \\
4,55 & 1,92 & 0,52 & 4,49 \\
4,54 & 1,92 & 0,52 & 4,49 \\
4,53 & 1,92 & 0,52 & 4,49 \\
4,45 & 1,92 & 0,52 & 4,49 \\
4,46 & 1,92 & 0,87 & 4,49 \\
\hline
\end{tabular}

yang berfungsi memproses konversi data paralel menjadi serial atau sebaliknya. Pada penelitian ini, fungsi tersebut terintegrasi ke dalam mikrokontroler dan bekerja secara otomatis sehingga keluaran data dari P1.0 dan P1.1 yang bersifat paralel langsung dikonversi secara serial dan siap dikeluarkan melalui P3.0 dan P3.1 yang merupakan port komunikasi serial dari mikrokontroler.

Kesederhanaan rangkaian elektronik memberikan resolusi untuk pengukuran waktu hingga $0,75 \times 10^{-1} \mathrm{~s}$, dan resolusi secara integral dari sistem adalah $10^{-1} \mathrm{~s}$, nilai resolusi ini merupakan resolusi waktu secara integral antara rangkaian hardware dan sistem software akuisisi. Metode pengukuran kecepatan bola jatuh yang dilakukan oleh Fujita et al. (2005) menggunakan prinsip interferometer Michelson dengan merekam citra atau video selama bola jatuh menggunakan CCD camera. Citra diproses untuk mendapatkan waktu jatuh dengan menganalisis pergeseran pixel antara gambar pertama dan kedua, sehingga didapatkan waktu tempuh, sistem ini mempunyai ketelitian hingga $10^{-4} \mathrm{~s}$ namun memerlukan waktu

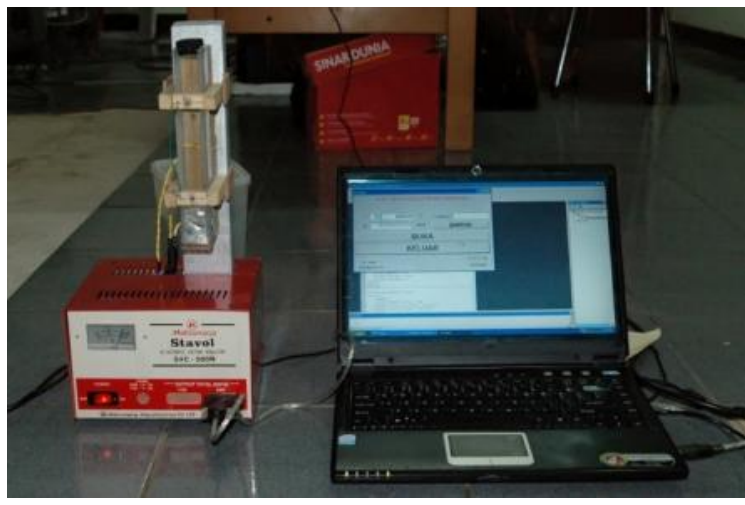

Gambar 4 Foto dari sistem secara keseluruhan

analisis yang bertahap dan lama serta belum bersifat real time memberikan data viskositas yang diukur.

Analisis Perangkat Lunak dari Sistem. Penelitian ini menggunakan dua bahasa pemrograman yaitu: Assembler dan Visual Basic 6.0. Bahasa pemrograman Assembler digunakan untuk proses pengendalian sinyal internal di mikrokontroler, sedangkan bahasa pemrograman Visual Basic 6.0 untuk proses akuisisi, perhitungan, penampilan, dan penyimpanan.

Program utama pada mikrokontroler adalah sebagai berikut:

\section{SENSOR1:}

JB P1.0,SENSOR2 ;JIKA P1.0 = 1 LOMPAT KE SENSOR2 MOV A,\#0OH ;ISI AKUMULATOR ADENGAN 0

ACALL KIRIM_DATA ;PANGGIL SUBRUTIN KIRIM_DATA

SJMP SENSOR1;KEMBALI KE LABEL SENSOR1

SENSOR2: 
JB P1.1,SENSOR1 ;JIKAP1.1 = 1 LOMPAT KE SENSOR1 MOV A,\#OFFH ; ISI AKUMULATOR ADENGAN 255

ACALL KIRIM_DATA ;PANGGIL SUBRUTIN KIRIM_DATA

\section{SJMP SENSOR2 ;KEMBALI KE LABEL SENSOR2}

Dimana program ini yang memberikan tanggapan ketika bola jatuh melewati sensor 1, akan otomatis memberikan perintah pada akumulator untuk mengisikan data 0 dan saat itu pencacahan waktu berjalan dengan resolusi $10^{-6} \mathrm{~s}$ sesuai dengan frekuensi kemampuan mencacah mikrokontroler dan kecepatan proses rutin program. Kesederhanaan program sangat mempengaruhi durasi eksekusinya, sehingga resolusi ini nantinya menyatu menjadi resolusi integral dari sistem. Ketika bola sampai pada sensor 2, maka mikrokontroler memberikan tanggapan untuk mengisi akumulator dengan 255. Sehingga mikrokontroler menghitung waktu antara sensor 1 dan sensor 2 .

Kemudahan dan kecepatan proses perhitungan data dilakukan semuanya pada program Visual Basic 6.0 yang tersimpan di komputer. Pengaksesan port serial pada komputer menggunakan Visual Basic 6.0 dapat dilakukan dengan menggunakan control MSComm tanpa harus membuat program tambahan. Pada pemrograman ini dilakukan koneksi dengan Microsoft Acces sebagai database-nya. Kemudian dilakukan setting Port serial, aktivasi database, dan koneksi dengan database. Selanjutnya terdapat program yang melakukan proses pembacaan data serial, dimana data tersebut dikirim oleh mikrokontroler. Program untuk menghitung selisih waktu ketika bola lewat sensor 1 dan sensor 2 adalah sebagai berikut:

Private Sub MSComm1_OnComm()

' Jika terjadi penerimaan data maka data diterima

If MSComm1.CommEvent = comEvReceive Then

SBUF $=$ MSComm1.Input

data $=$ Asc $($ SBUF $)$

If data $=255$ Then

SetTimer Me.hwnd, 0, 1, AddressOf FormatLabel

End If

If data $=0$ Then

jumlahwaktu $=$ Timer

KillTimer Me.hwnd, 0

waktuberhenti $=$ Timer - jumlahwaktu

End If

End If

Pada program di atas, terlihat pada saat jeda antara tanggapan sensor pertama dan sensor kedua, sistem komputer menjalankan program pencacahan internal (SetTimer). Frekuensi timer sesuai dengan karakteristik komputer yang digunakan dan akan berhenti ketika terjadi tanggapan yang kedua yaitu bola melewati phototransistor kedua (KillTimer). Resolusi pencacahan oleh komputer sebesar $10^{-3} \mathrm{~s}$, resolusi ini harus mempunyai kecepatan lebih tinggi dari pada kecepatan respon rangkaian secara integral sehingga tidak mengurangi resolusi sistem dan sistem pencacahan tetap mempunyai resolusi sebesar $0,75 \times 10^{-1} \mathrm{~s}$.

Analisis Hasil Pengukuran. Hasil pencatatan waktu tempuh dan perhitungan viskositas gliserin seperti tampak pada Tabel 2. Perhitungan nilai viskositas gliserin tersebut telah memperhitungkan nilai faktor koreksi kecepatan bola jatuh sebagai fungsi rasio diameter bola jatuh terhadap tabung. Dari Tabel 2 terlihat bahwa nilai viskositas tanpa memperhitungkan faktor koreksi $\eta_{0}$ sebesar 3222,7977 $\pm 3,6721$ mPa.s.

Nilai faktor koreksi kecepatan bola jatuh sebagai fungsi rasio diameter bola terhadap diameter tabung tampak seperti pada Gambar 5, Data 1 merupakan hasil simulasi menggunakan persamaan yang diberikan oleh Brizard et al. (2005) yang telah dimodifikasi untuk faktor rasio yang sangat kecil. Brizard et al. (2005), membatasi bahwa persamaan yang mereka berikan hanya untuk maksimum d/D $<0,6$. Sedangkan grafik Data 2 pada Gambar 5, merupakan simulasi dari faktor koreksi yang diberikan oleh Francis (1933). Kedua simulasi tersebut memberikan nilai faktor koreksi yang sama untuk $0,01<\mathrm{d} / \mathrm{D}<$ 0,16, sedangkan di atas nilai tersebut faktor koreksi tersebut mulai menunjukkan nilai yang berbeda.

Hasil perhitungan viskositas gliserin ç, menggunakan faktor koreksi $C_{f}$ berdasarkan persamaan Francis (1933), memberikan nilai sebesar 1675,8548 $\pm 1,9095 \mathrm{mPa} . \mathrm{s}$, dimana nilai faktor koreksi $C_{f}$ yang dipergunakan sebesar 0,5246. Sedangkan dengan menggunakan persamaan faktor koreksi $C_{f}$ yang telah disimulasikan pada Gambar 5 memberikan nilai

Tabel 2 Hasil pengukuran waktu tempuh dan hasil perhitungan viskositas gliserin

\begin{tabular}{cccc}
\hline Waktu (s) & $\eta 0$ & $\eta 1$ (mPa.s) & $\eta 2$ (mPa.s) \\
\hline 251,7071 & 3239,6773 & 1425,4580 & 1684,6322 \\
250,4181 & 3223,0860 & 1418,1579 & 1676,0047 \\
251,8501 & 3241,5171 & 1426,2675 & 1685,5889 \\
249,5506 & 3211,9212 & 1413,2453 & 1670,1990 \\
250,7279 & 3227,0737 & 1419,9124 & 1678,0783 \\
249,1530 & 3206,8029 & 1410,9933 & 1667,5375 \\
249,7175 & 3214,0691 & 1414,1904 & 1671,3159 \\
251,8639 & 3241,6950 & 1426,3458 & 1685,6814 \\
249,7141 & 3214,0250 & 1414,1710 & 1671,2930 \\
251,0100 & 3230,7052 & 1421,5103 & 1679,9667 \\
249,7071 & 3213,9357 & 1414,1317 & 1671,2465 \\
248,8639 & 3203,0825 & 1409,3563 & 1665,6029 \\
250,8604 & 3228,7797 & 1420,6631 & 1678,9654 \\
\hline
\end{tabular}




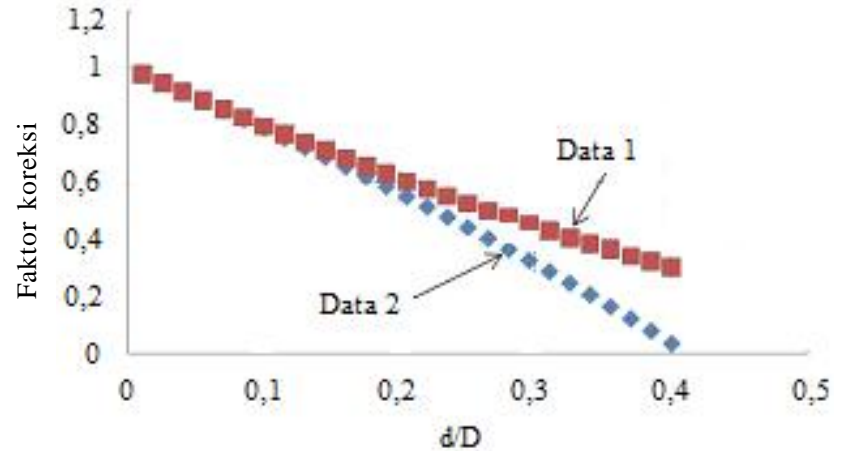

Gambar 5 Hasil simulasi nilai faktor koreksi kecepatan bola jatuh sebagai fungsi rasio diameter bola terhadap diameter tabung (Data 1) dan berdasarkan persamaan Francis (1933) (Data 2)

viskositas gliserin ç, sebesar 1418,0309 $\pm 1,6157 \mathrm{mPa}$.s dengan nilai faktor koreksi sebesar 0,4425 dan pengukuran pada suhu $20^{\circ} \mathrm{C}$. Nilai baku dari viskositas gliserin pada suhu $20^{\circ} \mathrm{C}$ yang diberikan oleh Dorsey (1940) adalah sebesar 1410 mPa.s., sehingga hasil pengukuran pada penelitian ini memberikan nilai kesalahan ketepatan $\left(\stackrel{\circ}{a}_{0}\right)$ sebesar $0,57 \%$. Hasil pengukuran viskositas gilserin pada penelitian ini lebih dekat kepada hasil penelitian yang dilakukan oleh Han et al. (2008), yaitu sebesar $1420 \mathrm{mPa}$.s. pada suhu $20^{\circ} \mathrm{C}$, sehingga memberikan nilai kesalahan ketepatan $\left(\stackrel{\circ}{a}_{0}\right)$ sebesar $0,14 \%$.

\section{SIMPULAN}

Telah dilakukan desain dan analisis sistem pengukuran viskositas menggunakan sensor optocoupler dan sistem akuisisinya yang berfungsi dengan baik. Dua rangkaian sensor optocoupler digunakan sebagai sistem pengukuran waktu pada bola jatuh dengan melalui dua titik referensi. Sistem akuisisi komputer yang dipergunakan adalah komunikasi serial dengan resolusi $0,75 \times 10^{-1} \mathrm{~s}$, sedangkan secara keseluruhan, sistem mempunyai resolusi pengukuran waktu sebesar $10^{-1} \mathrm{~s}$. Nilai viskositas dari gliserin pada suhu $20^{\circ} \mathrm{C}$ hasil dari pengukuran adalah sebesar 1418,0309 $\pm 1,6157$ mPa.s., nilai ini sangat dekat dengan hasil pengukuran Han $d k k$ (2008) yaitu sebesar 1420 mPa.s. sehingga kesalahan ketepatan $\left(\stackrel{\circ}{a}_{0}\right)$ sebesar $0,14 \%$.

\section{UCAPAN TERIMA KASIH}

Penulis mengucapkan terima kasih kepada DP2M, Dirjend Dikti yang telah memberikan support dana penelitian melalui program Penelitian Hibah Kompetensi dengan No Kontrak : 529/SP2H/PP/DP2M/VII/2010 tanggal 24 Juli 2010.

\section{DAFTAR PUSTAKA}

Brizard, M., Megharfi, M., Fredier, C \& Mahe, E. 2005. Design of a high precision falling ball viscosimeter, Review of Scientific Instruments 76 (2).

Dorsey, N.E. 1940. Properties of ordinary water substance. New York press.

Francis, Alfred W. 1933. Wall effect in falling ball method for viscosity. Physics 4, 403.

Fujita, Yoshitaka, Naoki Kuramoto, Yasumitsu Kurano \& Kenichi Fujii. 2003. An absolute measurement of the viscosity by the falling ball method. Proceeding of $14^{\text {th }}$ Conference on the Properties of Water and Steam in Kyoto.

Fujita, Yoshitaka, Naoki Kuramoto, Yasumitsu Kurano \& Kenichi Fujii. 2005. A study on an absolute measurement of the viscosity by the Falling Ball Method for a primary viscosity standard : development of a velocity measurement system for falling ball. Thermophysics Journal. Volume 26 Page 430-432.

Gottlieb \& Moshe. 1979. Zero-shear-rate viscosity measurements for polymer solutions by falling ball viscometry. Journal of Non-Newtonian Fluid Mechanics. Volume 6, Issue 2, 1979, Pages 97-109.

Han, Aijie, Weiyi Lu, K Puryamutula, Xi Chen \& Falgun B Surani. 2008. Effective viscosity of glycerin in a nanoporous silica gel. Journal of Applied Physics. 104. 124908.

Hinrichs, Richard, J \& Judy Thuen. 1985. Method for determining resin viscosity with ultrasonic waves. United States Patent. Number 4559810, 24 December.

Leont'ev, A.P \& Vakhrushev, I.A. 1976. Experimental determination of effective viscosity of fluidized beds by falling-ball method. Chemistry and Technology of Fuels and Oils. Volume 12, Number 4, 294-297.

Lommatzsch T, Megharfi, M, Mahe, E \& Devin, E. 2001. Conceptual study of an absolute falling-ball viscometer. Metrologia. 38531.

Thibodeau, \& Len. 2004. Measuring viscosity of pastes. American Laboratory News. Volume: June.

Truell, R., Elbaum, C \& Chick, B. 1969. Ultrasonic methods in solid state physics. Academic Press, New York and London.

Walters, K \& Jones, W. N. 1996. Measurement of Viscosity. Instrumentation Reference Book. Butterworth Heineman, Oxford.

Warsito, Sri Wahyu Suciyati \& Andriyanto. 2009. Analisis pemanfaatan mikrokontroler AT89C51 sebagai pemroses system pencacah putaran objek berputar : prospektif sebagai alat uji kelelahan oli. Proseding Seminar Nasional Sains MIPA dan Aplikasinya. 1,() 453 - 462.

Warsito, Sri Wahyu Suciyati \& Romi Akbar. 2010. Transduser Ultasonik Tipe MA40E7R/5 Waterproof untuk mengukur viscositas fluida. In press. 